\title{
Bile Acid Efflux from Suckling Rat Hepatocytes
}

\author{
WILLIAM M. BELKNAP,' LINDA ZIMMER-NECHEMIAS, FREDERICK J. SUCHY, AND \\ WILLIAM F. BALISTRERI
}

Children's Hospital Research Foundation, Cincinnati, Ohio 45229

\begin{abstract}
To further assess bile acid transport by the developing rat liver, we compared the rate of efflux of taurocholate from hepatocytes isolated from suckling and mature rat livers. Cell content of taurocholate (nmol/ mg cell protein), after preloading with $\left[{ }^{14} \mathrm{C}\right]$-radiolabeled plus cold bile acid (5-100 $\mu \mathrm{M})$ was similar in both groups. Total taurocholate efflux, estimated by the decrease in cell taurocholate content, was unexpectedly greater from suckling rat hepatocytes. There was a higher bile acid efflux rate over time and a lower final cell content. Efflux from suckling rat hepatocytes was increased after preloading in incubation concentrations of taurocholate which were above the physiologic range of portal blood concentrations. Inasmuch as the bile acid binding protein content is known to be reduced in the cytoplasm of developing rat liver, intracellular taurocholate may exist largely as free ligand and thus be more readily diffusable. We speculate that the in vivo correlation of enhanced efflux is back diffusion of bile acid from the cell into the sinusoid. The effect could, in part, account for the known absence of a lobular gradient for bile acid uptake in suckling rats and, therefore, contribute to the inefficient hepatic transport of bile acid observed in developing rat liver. (Pediatr Res 23: 364-367, 1988)
\end{abstract}

Bile acids are efficiently extracted from plasma by the normal liver and are secreted into bile, thereby serving as the major determinants of bile flow $(1,2)$. Bile formation by suckling rat liver is several-fold less than that of mature animals (3). Previous investigations have shown inefficiency of several aspects of the enterohepatic circulation of bile acids in developing rats. For example, serum bile acids in healthy suckling and weanling animals are elevated to levels comparable to those present in mature animals with induced cholestasis (4). Uptake of taurocholate, as observed in both isolated hepatocytes and basolateral membrane vesicles, is reduced $(5,6)$. Moreover, the functional reserve of hepatocytes for uptake within the hepatic lobule is reduced in early life, a feature demonstrated by absence of the normal portal to central lobular gradient for bile acid uptake (7). This very low basal hepatocellular extraction of bile acid exists in suckling rats despite reduced terminal ileal reabsorption. As a result, portal blood bile acid concentrations are far below those of mature rats. Hepatocellular uptake of bile acid eventually matures after weaning $(4-6,8)$. As ileal active transport of taurocholate matures earlier, the hepatic phase may be ratelimiting to the overall maturation of the enterohepatic circulation (9).

Received July 28, 1987; accepted December 7, 1987.

Correspondence William F. Balistreri. M.D., Children's Hospital Research Foundation, Pediatric Gastroenterology and Nutrition, Elland and Bethesda Avenues, Cincinnati, $\mathrm{OH} 45229$.

W.M.B. was a recipient of a Fellowship from the American Liver Foundation.

${ }^{1}$ Present address Department of Pediatrics, The University of Texas Health Science Center at Dallas, Southwestern Medical School, 5323 Harry Hines Boulevard, Dallas, TX 75235.
Little is known, however, about the hepatocellular compartmentation or secretion of bile acids during this phase of "physiologic cholestasis." Isolated hepatocytes have previously been used in several studies to assess bile acid excretion (10-15). Excretion or "efflux" of conjugated bile acid from hepatocytes isolated from rats with induced cholestasis has been shown to be reduced compared to control animals; this effect was attributed to reduced canalicular secretion (14). We hypothesized that hepatocytes from suckling rats, analogous to hepatocytes from animals with induced cholestasis, would show a different pattern of efflux compared to the normal adult rat. The aim herein, therefore, was to compare taurocholate efflux from hepatocytes of normal suckling and mature rats.

\section{MATERIALS AND METHODS}

Reagents. Reagents used herein included: $\left[24-{ }^{14} \mathrm{C}\right]$ taurocholate $(46.7 \mathrm{mCi} / \mathrm{mmol}),\left[{ }^{3} \mathrm{H}\right]$ inulin $(200 \mathrm{mCi} / \mathrm{g})$, and Aquassure Scintillation Cocktail, New England Nuclear Corporation (Boston, MA); sodium taurocholate (more than $98 \%$ pure by thin layer chromatography), Calbiochem (San Diego, CA); collagenase (type II), and bovine serum albumin (fraction V), Sigma Chemical Co. (St. Louis, MO); trypan blue, $0.4 \%$, GIBCO Laboratories (Grand Island, NY); and silicone oil, density $1.05 \mathrm{~g} / \mathrm{ml}$, Aldrich Chemical Co. (Milwaukee, WI). All reagents used in buffer preparation were of analytical grade and obtained from commercial sources. The buffer designated as " $A$ " (isolation buffer) contained the following: $140 \mathrm{mM} \mathrm{NaCl}, 5.4 \mathrm{mM} \mathrm{KCl}, 0.8 \mathrm{mM}$ $\mathrm{MgSO}_{4}, 0.8 \mathrm{mM} \mathrm{Na}_{2} \mathrm{HPO}_{4}, 25 \mathrm{mM} \mathrm{NaHCO}$, pH 7.40, $37^{\circ} \mathrm{C}$; buffer " $\mathrm{B}$ " (incubation buffer) consisted of $135 \mathrm{mM} \mathrm{NaCl}, 2 \mathrm{mM}$ $\mathrm{KCl}, 3 \mathrm{mM} \mathrm{KH}_{2} \mathrm{PO}_{4}, 0.3 \mathrm{mM} \mathrm{CaCl}, 1.0 \mathrm{mM} \mathrm{MgSO}_{4}, 10 \mathrm{mM}$ TRIS- $\mathrm{HCl}, 1 \% d$-glucose, and $2 \%$ bovine serum albumin.

Animals. Age-specific, male Sprague Dawley rats (Harlan, Inc., Indianapolis, IN) were used; suckling animals (mean body weight $28 \mathrm{~g}$ ) were used on the 14th day after birth. Mature animals were studied at 56 days of life, correlating to a mean body weight of $250 \mathrm{~g}$. All animals were housed in a temperature-controlled environment with alternating 12 -h light/dark cycles. On the day of experimentation, each animal was prepared in the fed state between 0900 and $1100 \mathrm{~h}$. All animals were given pentobarbital, $50 \mathrm{mg} / \mathrm{kg}$ body weight, intraperitoneally before experimentation. Eight rats were studied in each age group.

Hepatocyte isolation. Hepatocytes were isolated using the in situ collagenase perfusion method of Berry and Friend (16) with modifications as described previously $(5,17)$. Retrograde perfusion through the inferior vena cava was used to minimize the duration of interrupted hepatic blood flow. Livers from both age groups were perfused with buffer A at $2-4 \mathrm{ml} \cdot \mathrm{g}^{-1}$ liver $\cdot \mathrm{min}^{-1}$ until the organ was clear of blood. The buffer was continuously gassed using a $95 \% \mathrm{O}_{2} / 5 \% \mathrm{CO}_{2}$ mixture. Collagenase $(0.5 \mathrm{mg}$. $\mathrm{ml}^{-1}$ in buffer A) perfusion of the blood-free liver followed thereafter for $25 \mathrm{~min}$ or until the lobes visibly dissociated and fragmented from the liver capsule. The perfused, digested liver was then carefully excised in toto, placed in a beaker containing the collagenase solution, and gently minced with a scissors. A final 10-min incubation was then performed under a continuous 
stream of $95 \% \mathrm{O}_{2} / 5 \% \mathrm{CO}_{2}$ at $37^{\circ} \mathrm{C}$ in a rotatory bath to complete digestion of the liver. Hepatocytes were separated from undigested debris by filtering the initial suspension through a double layer of cheese cloth. The crude cell suspension was then washed three times by suspending in an excess volume of buffer $B$ and centrifuging at low speed $(50 \times \mathrm{g} \times 2 \mathrm{~min})$ to yield a preparation of more than $95 \%$ viable hepatocytes. The final cell pellet was resuspended in fresh buffer $\mathrm{B}$ at a concentration of $10^{6}$ viable cells/ml. Cell number was determined through counting in a hemocytometer. The freshly isolated liver cells from both age groups were $90-95 \%$ viable as assayed by Trypan blue exclusion before and at the completion of each experiment. Liver cell integrity was also suggested by minimal loss of intracellular lactic acid dehydrogenase into the incubation medium (less than $5 \%$ of original total cell homogenate activity per hour).

Taurocholate efflux experiments. The experimental design was to load isolated hepatocytes with bile acid at varying concentrations and then to resuspend the cells in bile acid-free buffer. In this manner, the final cell content after concentration-dependent movement of bile acid down the outwardly directed concentration gradient could be measured. Therefore, suspensions $(4 \mathrm{ml})$ of the isolated hepatocytes from each preparation were preloaded by incubating in buffer $\mathrm{B}$ containing radiolabeled $\left[{ }^{14} \mathrm{C}\right]$ taurocholate $(60 \mathrm{nCi} / \mathrm{ml})$ as tracer and increasing concentrations of unlabeled taurocholate $(5,10,25,50,100 \mu \mathrm{M})$. This concentration range was chosen to parallel the values that we have found to be present in portal venous blood of suckling (mean 25 , range 10 $36 \mu \mathrm{M})$ as well as mature rats (mean 80 , range $14-180 \mu \mathrm{M})(7$, 18). These concentrations allowed correlation of these data to the in vivo state and minimized the potential for bile acid toxicity to the cells.

The suspension was then incubated at $37^{\circ} \mathrm{C}$ in an atmosphere of $95 \% \mathrm{O}_{2} / 5 \% \mathrm{CO}_{2}$ in a water bath with continuous oscillation $(180 \mathrm{rpm} / \mathrm{min})$ for $15 \mathrm{~min}$, a time previously shown sufficient to achieve a steady state of intracellular bile acid (19). At the completion of taurocholate loading, duplicate $200-\mu$ l aliquots of each suspension were taken to estimate the postincubation intracellular taurocholate content. Adherent extracellular taurocholate, estimated by separate $\left[{ }^{3} \mathrm{H}\right]$ inulin experiments, was $<2 \%$ in both age groups in all experiments.

To assess efflux, the suspension of preloaded hepatocytes was centrifuged at low speed and the incubating buffer aspirated and discarded. The preloaded cell pellet was then resuspended in bile acid free buffer B and timing begun. Duplicate $200-\mu 1$ aliquots were then withdrawn from the new cell suspension at timed intervals $(15,30,45,60,105$, and $300 \mathrm{~s})$ and placed in $400-\mu 1$ polyethylene tubes previously layered with $50 \mu \mathrm{l}$ of $3 \mathrm{M} \mathrm{KOH}$ beneath $100 \mu \mathrm{l}$ of silicone oil. The samples were immediately centrifuged $(15,000 \times g)$ for 10 seconds in a rapidly accelerating table-top microfuge (Beckman Instruments, Fullerton, CA). This caused the viable cells to sediment through the oil into the $\mathrm{KOH}$. The cell pellet was allowed to dissolve in $\mathrm{KOH}$ for $18-24 \mathrm{~h}$. To determine the amount of $\left[{ }^{14} \mathrm{C}\right]$ labeled bile acid in the cell pellet at each time point, the polyethylene tubes were cut at the oil$\mathrm{KOH}$ interface and each portion placed in individual scintillation vials. The cell pellet in $\mathrm{KOH}$ was neutralized with $75 \mu \mathrm{l}$ of $2 \mathrm{~N}$ $\mathrm{HCl}$. Scintillation cocktail $(3 \mathrm{ml})$ was added, and cell radioactivity was measured by liquid scintillation counting with external standardization for quench correction. Protein content in additional sample aliquots was determined by the method of Lowry with bovine serum albumin as standard (20). Results were expressed as nmoles of bile acid/mg of cell protein.

Data analysis. Student's $t$ tests were used where indicated as a significance criterion for differences between means of cell and supernatant content of taurocholate.

\section{RESULTS AND DISCUSSION}

Influx of taurocholate at varying preloading concentrations $(5-100 \mu \mathrm{M})$ reached equilibrium by $15 \mathrm{~min}$ in both suckling and adult rat hepatocytes. The resulting intracellular taurocholate content in both groups was similar at each preloading concentration (Fig. 1). Thus the intracellular space/mg of cell protein available for equilibration with extracellular taurocholate did not appear to change with age.

Efflux, defined as the measured decrease in cell content of taurocholate, was linear over a 300 -s period in both groups. The cell taurocholate content at $300 \mathrm{~s}$ was significantly lower in suckling compared with adult hepatocytes at preloading concentrations of 50 and $100 \mu \mathrm{M}$ (Fig. 2).

Our data show that suckling rat hepatocytes exhibit a greater rate of taurocholate efflux than do comparably isolated mature rat hepatocytes. Cell loading with taurocholate revealed identical starting content in both groups (Fig. 1). The efflux observed was greater in cells from the younger animals with increasing preloading; while a tendency was apparent at $25 \mu \mathrm{M}$, a significant difference occurred at 50 and $100 \mu \mathrm{M}$. Greater efflux occurred with incubation in bile acid concentrations above the in vivo portal blood bile acid concentration range of both groups. The observation of significantly less cell taurocholate at $5 \mathrm{~min}$ in the suckling rat hepatocytes with increasing preloading demonstrated their enhanced propensity to release taurocholate. Enhanced bile acid efflux in suckling rats was induced only by preloading them in concentrations of taurocholate in excess of their physiologic portal venous concentrations $(5,21,22)$.

Although the suckling rat is a model for "physiologic choles-

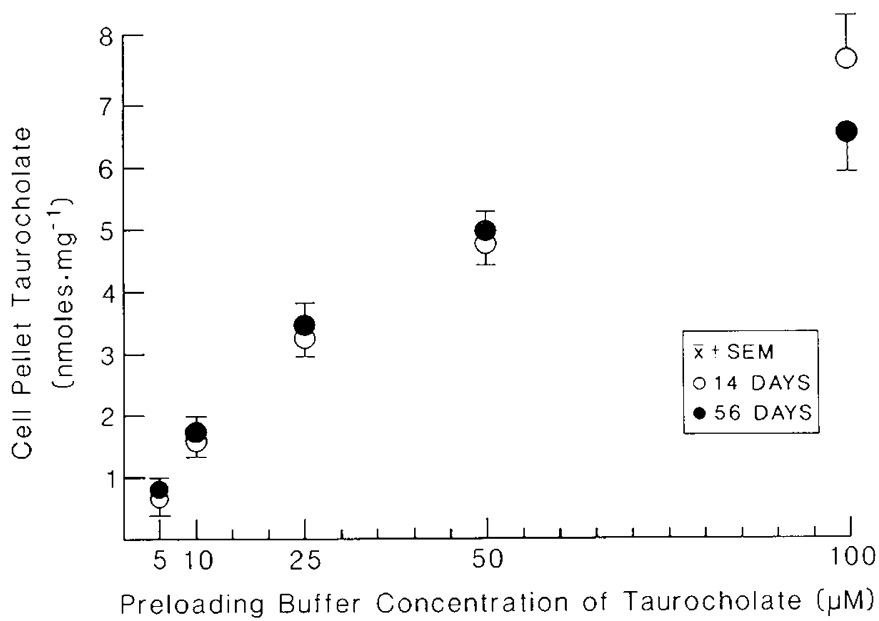

Fig. 1. The cell content of taurocholate after incubation at each taurocholate concentration was similar when corrected for cell protein. The groups were disparate at $100 \mu \mathrm{M}$, but this was not a significant difference.

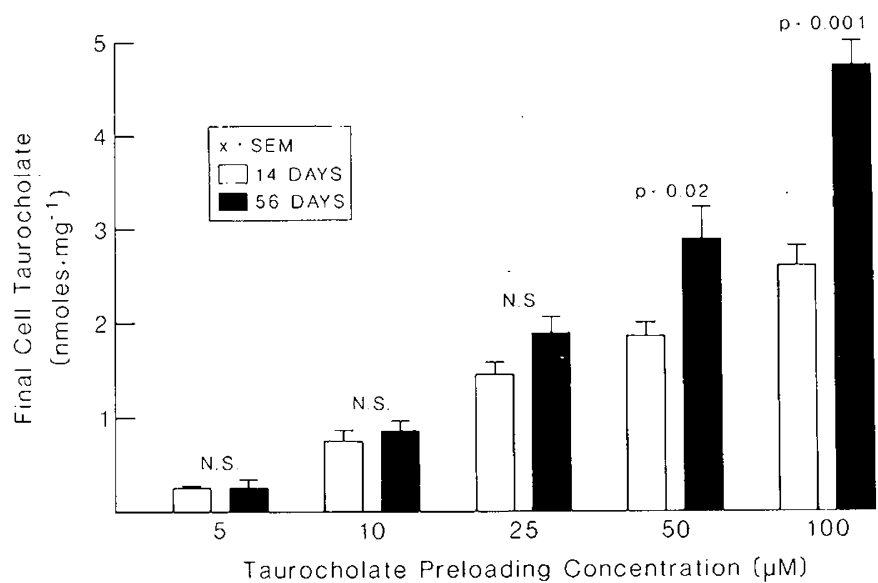

Fig. 2. The final cell pellet taurocholate content $\left(\mathrm{nmol} \cdot \mathrm{mg}^{-1}\right)$ is plotted against the original preincubation concentration. The inability of suckling hepatocytes to retain taurocholate is apparent with greater preloading. This effect is statistically different from mature cells above $25 \mu \mathrm{M}$. 
tasis," the observed enhanced efflux rate is in contrast to the reduced rate seen in mature rats after induced cholestasis (14). Extraction (5) and metabolism (23) of bile acids are inefficient in suckling rat hepatocytes; therefore, it is unlikely that the difference in efflux observed can be hypothetically explained by movement across the apical, secretory pole of the hepatocyte. The maximal velocity of uptake is markedly less than that of mature hepatocytes, therefore an adequate assessment of the secretory capabilities would require isolation of the canalicular membrane fraction from suckling rat liver (24). As the findings herein in suckling rats with physiologic cholestasis are not reconcilable with those observed in induced cholestasis of adult animals, other speculative explanations are necessary.

The physicochemical properties of hepatocytes of suckling rats could be different than those isolated from fully developed animals. Membrane diffusion constants for taurocholate may be different in mature and suckling rat hepatocytes, perhaps favoring diffusion in the latter. A different plasma membrane lipid environment in the suckling rat hepatocyte could explain the magnitude of disparity observed. The electrical gradient present in the mature hepatocyte is unfavorable for taurocholate uptake (1); an increase in the electronegative intracellular environment would favor outward movement. Consistent with this hypothesis, enhanced rates of taurocholate efflux from mature rat isolated hepatocytes have been observed after coincubation with agents known to cause membrane hyperpolarization, such as $\alpha$-adrenergics (34). The induced increase in intracellular negativity results in stimulation of efflux of negatively charged bile acid. Therefore, if the suckling rat hepatocyte possesses a greater intracellular electronegativity, the result could hypothetically be larger rates of taurocholate efflux. The transmembrane potential difference in this model, however, remains unknown.

An alternate path to canalicular release of bile acid from isolated hepatocytes is via back diffusion across the sinusoidal membrane; this has been described for both bilirubin (25) and bile acid (26) in the isolated, perfused, mature rat liver model. Sinusoidal back diffusion subtracts only minimally from net transport of taurocholate across the mature liver despite a large chemical back gradient. The experimental effect of back diffusion will, however, increase with rising initial intracellular concentrations (26). The efficiency of hepatocellular bile acid concentrative transport, nonetheless, allows large amounts of ligand to accumulate above incubation concentrations despite saturating the canalicular secretory mechanism (26). This has been seen in isolated cells (19) or in monolayer cultures of hepatocytes (15). We have also found that the mean systemic serum bile acid concentration is less than $3 \mu \mathrm{M}$ in the adult rat, despite portal blood concentrations which may exceed $300 \mu \mathrm{M}(21,22)$, an observation consistent with this hypothesis. These data indicate that the fate of intracellular bile acid in intact mature rat liver is directed predominantly to the canalicular lumen with negligible back diffusion. In contrast, in the suckling rat portal venous bile acid concentrations are lower than in the adult; however, systemic levels are 10 -fold higher reflecting either impaired hepatic clearance or a cellular inability to concentrate bile acid (4).

Based on the current study, back diffusion may have physiologic significance in suckling rat liver. There are data from other investigations to support this hypothesis. One factor that potentially serves to prevent back diffusion is binding of ligand to soluble binding proteins; this may allow retention of organic anions within the hepatocellular cytoplasm despite a large chemical back gradient. Glutathione-S-transferase B (ligandin), which binds several organic anions, has been shown to prevent the sinusoidal back diffusion of bilirubin from the cytoplasm (25). Ligandin demonstrates in vitro bile acid binding (27), and fractionation studies have shown that the principal intracellular location of bile acids is the same as ligandin, the cytoplasm (22, 28). Interestingly, the cytoplasmic content of ligandin in 1-wkold rat pups is one-fifth that of mature rat hepatocyte content and requires nearly 6 postnatal wk to approach adult levels (29).
In addition, a new class of cytoplasmic bile acid binding protein has recently been described (30). We have determined that the content of this second cytosolic bile acid binding protein in rat liver during the $1 \mathrm{st}$ wk of life is approximately one-half of that present later in development and in fully grown animals (31). In suckling rat liver, therefore, diminished protein binding could dramatically influence the intracellular solute activity of bile acids by permitting a greater pool of free ligand. This could potentiate a more rapid efflux in suckling rat hepatocytes as observed herein. Also, it would corroborate the observation that efflux increases with rising initial cell content, paralleling an expanding free pool. The net effect is that taurocholate will not accumulate within the hepatocyte above the capacity of binding proteins native to suckling rat liver in the absence of a large, inwardly directed concentration gradient. This could explain our observation that suckling rat hepatocytes were able to attain a bile acid concentration similar to mature cells during preloading despite a lower initial uptake velocity as documented earlier (5). Earlier and greater "unloading" seemed to occur once this large inward gradient was removed.

Factors other than soluble protein binding could also theoretically alter the intracellular solute activity of taurocholate in suckling rat liver. A feature that must be examined is the role of variations in metabolism by the immature hepatocyte compared to the mature cell. For example, hydroxylation, conjugation, and detoxification may alter the physicochemical properties of the bile acid $(32,33)$. The role of this factor must be examined in the future by determining the nature of the effluxed, labeled bile acid species.

In summary, enhanced taurocholate efflux in all likelihood cannot be explained through a single mechanism. As isolated hepatocytes lack the separate canalicular and sinusoidal membrane domains, a firm conclusion regarding the path and mechanism of enhanced efflux cannot be made. The magnitude of efflux observed implies movement back across a large surface area such as that of the sinusoidal domain, although this remains unproven. The in vivo correlation of enhanced efflux seen in suckling rat hepatocytes would be sinusoidal back diffusion in the intact liver of the developing animal which would further contribute to the inefficiency of bile acid transport. This could also account for the observed absence of a lobular gradient and a higher systemic to portal ratio of serum bile acid levels in early life. This overall hypothesis is also consistent with the observation that developing liver has a greater propensity to experience hepatocellular bile secretory failure (4). Future investigations should further address the integrity and physical environment of the bile secretory apparatus in developing mammalian liver.

\section{REFERENCES}

1. Blitzer BL, Boyer JL 1982 Cellular mechanisms of bile formation. Gastroenterology 82:346-357

2. Boyer JL $1980 \mathrm{New}$ concepts of mechanisms of hepatocyte bile formation. Physiol Rev 60:303-326

3. Ballatori N, Clarkson TW 1982 Developmental changes in the biliary excretion of methylmercury and glutathione. Science 216:61-63

4. Belknap WM, Balistreri WF, Suchy FJ, Miller PC 1981 Physiologic cholestasis II: Serum bile acid levels reflect the development of the enterohepatic circulation in rats. Hepatology 1:613-616

5. Suchy FJ, Balistreri WF 1982 Uptake of taurocholate by hepatocytes isolated from developing rats. Pediatr Res 16:282-285

6. Suchy FJ, Blitzer BL 1985 Taurocholate transport by basolateral liver plasma membrane vesicles isolated from developing rats. Am J Physiol 248:G648654

7. Suchy FJ, Balistreri WF, Breslin JS, Dumaswala R, Setchell KDR, Garfield SA 1987 Absence of an acinar gradient for bile acid uptake in developing rat liver. Pediatr Res 21:417-421

8. Suchy FJ, Balistreri WF, Hung J, Miller P, Garfield SA 1983 Intracellular bile acid transport in rat liver as visualized by electron microscope autoradiography using a bile acid analogue. Am J Physiol 245:G681-689

9. Heubi JE, Suchy FJ, Rigney JL 1982 Ontogeny of intestinal bile salt transport in the rat. Gastroenterology 82:1038

10. Anwer MS, Kroker R, Hegner D 1975 Bile acids secretion and synthesis by isolated rat hepatocytes. Biochem Biophys Res Comm 64:603-609 
11. Gardner B, Chenouda MS 1978 Studies of bile acid secretion by isolated rat hepatocytes. J Lipid Res 19:985-991

12. Kempen HJM, Vos-Van Holstein MPM, deLange J 1982 Bile acids and lipids in isolated rat hepatocytes: content, synthesis, and release, as affected by cholestyramine treatment of the donor rats. J Lipid Res 22:823-830

13. Schwarz LR, Schwenk M, Pfaff E, Greim H 1976 Excretion of taurocholate from isolated hepatocytes. Eur J Biochem 71:369-383

14. Tarao K, Olinger EJ, Ostrow JD, Balistreri WF 1982 Impaired bile acid efflux from hepatocytes isolated from the liver of rats with cholestasis. Am J Physiol 243:G253-258

15. VanDyke RW, Stephens JE, Scharschmidt BF 1982 Bile acid transport in cultured rat hepatocytes. Am J Physiol 243:G4841-492

16. Berry MN, Friend DS 1969 High-yield preparation of isolated rat liver parenchymal cells, a biochemical and fine structural study. J Cell Biol 43:506-520

17. Bissell DM, Hammaker LE, Meyer UA 1973 Parenchymal cells from adult rat liver in nonproliferating monolayer culture. J Cell Biol 59:722-734

18. Balistreri WF, Belknap WM, Suchy FJ, Zimmer-Nechemias L 1985 Immaturity of the enterohepatic circulation of bile acids in early life: factors responsible for increased peripheral serum bile acid concentrations. In: Proceedings of Falk Symposium no. 42, VIII International Bile Acid Meeting, Berne, Switzerland, pp 87-93

19. Schwarz LR, Burr R, Schwenk M, Pfaff E, Griem H 1975 Uptake of taurocholate acid into isolated rat liver cells. Eur $\mathrm{J}$ Biochem 55:617-623

20. Lowry OH, Rosebrough NJ, Farr AL, Randall RJ 1951 Protein measurement with the Folin phenol reagent. J Biol Chem 193:265-275

21. Cronholm T, Sjovall $\mathbf{J} 1967$ Bile acids in portal blood of rats fed different diets and cholestyramine. Eur J Biochem 2:375-383

22. Okishio T, Nair PP 1966 Studies on bile acids: some observations on the intracellular localization of major bile acids in rat liver. Biochemistry 5:3662 3668

23. Suchy FJ, Courchene SM, Balistreri WF 1985 Ontogeny of hepatic bile acid conjugation in the rat. Pediatr Res 19:97-101
24. Inoue M, Kinne R, Tran T, Biempica L, Arias IM 1983 Rat liver canalicular membrane vesicles: Isolation and topological characterization. J Biol Chem 258:5183-5188

25. Wolkoff AW, Goresky CA, Sellin J 1979 Role of ligandin in transfer of bilirubin from plasma into liver. Am J Physiol 236:E638-648

26. Dietmaier A, Gosser R, Graf J, Peterlik M 1976 Investigations on the sodium dependence of bile acid fluxes in the isolated perfused rat liver. Biochim Biophys Acta 443:81-91

27. Strange RC, Cramb R, Hayes JD, Percy-Robb IW. Partial purification of two lithocholic acid-binding proteins from rat liver 100,000 g supernatants. Biochem J 165:425-429

28. Strange RC, Chapman BT, Johnston JD, Nimmo IA, Percy-Robb IW 1979 Partitioning of bile acids into subcellular organelles and the in vivo distribution of bile acids in rat liver. Biochim Biophys Acta 573:535-545

29. Hales BF, Neims AH 1976 Developmental aspects of glutathione-S-transferase B ligandin in rat liver. Biochem J 160:231-236

30. Sugiyama Y, Yamada T, Kaplowitz N 1983 Newly identified bile acids binders in rat liver cytosol: purification and comparison with glutathione S-transferases. J Biol Chem 258:3602-3607

31. Stolz A, Sugiyama Y, Kuhlenkamp J, Osadchey B, Yamada T, Belknap W, Balistreri W, Kaplowitz N 1986 Cytosolic bile acid binding protein in rat liver: radioimmunoassay, molecular forms, developmental characteristics and organ distribution. Hepatology 6:433-439

32. Balistreri WF, Zimmer L, Suchy FJ, Bove KE 1984 Bile salt sulfotransferase: alterations during maturation and non-inducibility during substrate ingestion alterations during matura

33. Karlaganis G, Sjovall J 1984 Formation and metabolism of bile alcohols in man. Hepatology 4:966-973

34. Gerwirtz DA, Randolph JK, Goldman ID 1984 Induction of taurocholate released from isolated rat hepatocytes in suspension by $\alpha$-adrenergic agents and vasopressin: Implications for control of bile salt secretion. Hepatology $4: 205-212$ 